\title{
Interleukin-1 $\beta$ Biosynthesis Inhibition Reduces Acute Seizures and Drug Resistant Chronic Epileptic Activity in Mice
}

\author{
Mattia Maroso, ${ }^{1}$ Silvia Balosso, ${ }^{1}$ Teresa Ravizza, ${ }^{1}$ Valentina Iori, ${ }^{1}$ Christopher Ian Wright, ${ }^{2}$ \\ Jacqueline French, ${ }^{3}$ and Annamaria Vezzani ${ }^{1}$ \\ ${ }^{I}$ Department of Neuroscience, Mario Negri Institute for Pharmacological Research, Milano, 20156 Italy; ${ }^{2}$ Vertex Pharmaceuticals \\ Inc., Cambridge, Massachusetts 02139; and ${ }^{3}$ New York University Comprehensive Epilepsy Center, New York, New York 10016
}

\begin{abstract}
Summary: Experimental evidence and clinical observations indicate that brain inflammation is an important factor in epilepsy. In particular, induction of interleukin-converting enzyme (ICE)/caspase-1 and activation of interleukin (IL)- $1 \beta$ / IL-1 receptor type 1 axis both occur in human epilepsy, and contribute to experimentally induced acute seizures. In this study, the anticonvulsant activity of VX-765 (a selective ICE/ caspase-1 inhibitor) was examined in a mouse model of chronic epilepsy with spontaneous recurrent epileptic activity refractory to some common anticonvulsant drugs. Moreover, the effects of this drug were studied in one acute model of seizures in mice, previously shown to involve activation of ICE/caspase-1. Quantitative analysis of electroencephalogram activity was done in mice exposed to acute seizures or those developing chronic epileptic activity after status epilepticus to assess the anticonvulsant effects of systemic administration of VX-765.
\end{abstract}

Histological and immunohistochemical analysis of brain tissue was carried out at the end of pharmacological experiments in epileptic mice to evaluate neuropathology, glia activation and IL-1 $\beta$ expression, and the effect of treatment. Repeated systemic administration of VX-765 significantly reduced chronic epileptic activity in mice in a dose-dependent fashion $(12.5-200 \mathrm{mg} / \mathrm{kg})$. This effect was observed at doses $\geq 50 \mathrm{mg} /$ $\mathrm{kg}$, and was reversible with discontinuation of the drug. Maximal drug effect was associated with inhibition of IL-1 $\beta$ synthesis in activated astrocytes. The same dose regimen of VX-765 also reduced acute seizures in mice and delayed their onset time. These results support a new target system for anticonvulsant pharmacological intervention to control epileptic activity that does not respond to some common anticonvulsant drugs. Key Words: Astrocytes, anticonvulsant drug, inflammation, IL-1 $\beta$, temporal lobe epilepsy.

\section{INTRODUCTION}

Experimental seizures in rodents induce inflammatory processes in brain regions in which epileptic activity originates and spreads $[1,2]$; in this respect, the activation of the interleukin (IL)-1 $\beta / \mathrm{IL}-1$ receptor type 1 (R1) signaling in glia and neurons is a key event contributing to intrinsic brain inflammation [3-12]. Paracrine and autocrine activation of this signaling by the brain application of IL-1 $\beta$ exacerbates kainic acid- or bicuculline-induced seizures in rats and mice $[5,11,13]$, and lowers the seizure threshold in febrile seizure models $[7,8]$. Conversely, IL-1 receptor antagonist (the naturally

Mattia Maroso and Silvia Balosso contributed equally to this study. Electronic supplementary material The online version of this article (doi:10.1007/s13311-011-0039-z) contains supplementary material, which is available to authorized users.

Address correspondence and reprint requests to: Annamaria Vezzani, Phd., Department of Neuroscience, Mario Negri Institute for Pharmacological Research, Milano, 20156 Italy. E-mail: vezzani@marionegri. occurring competitive antagonist of IL-1R1) mediates powerful anticonvulsant effects in rodents $[6,13-15]$ and mice over-expressing IL-1 receptor antagonist in astrocytes, or lacking IL-1R1, are intrinsically less susceptible to seizures [7, 13]. These data indicate the important involvement of elevated brain IL- $1 \beta$ levels and the activation of IL-1R1 signaling in experimental seizures.

Our earlier studies explored whether seizures induced acutely in naïve rats were affected by the blockade of IL$1 \beta$ biosynthesis. Using either pralnacasan or VX-765 (two selective inhibitors of interleukin-converting enzyme (ICE)/caspase-1 [16], the key enzyme specifically involved in the production of the releasable and biologically active form of IL-1 $\beta$ [17]), we found a significant decrease in acute seizure activity induced by intracerebral injection of kainic acid [9], and the arrest of seizure generalization in the kindling model of epileptogenesis [12].

There is evidence of increased levels of IL- $1 \beta$ and IL1R1, and ICE/caspase-1 activation [18] in surgically 
resected epileptogenic tissue from pharmaco resistant patients with temporal lobe epilepsy (TLE) or malformations of cortical development [10, 19-22], suggesting that the IL-1 $\beta / I L-1 R 1$ axis is activated in human epilepsy as in experimental models.

The objective of this study was to establish whether ICE/caspase-1 inhibition by VX-765 could suppress spontaneous recurrent epileptic activity by using a mouse model, which recapitulates some of the salient neuropathological sequelae of TLE, and in which epileptic activity does not respond to some commonly used antiepileptic drugs (AEDs) [23, 24]. Moreover, because VX-765 effect on acute seizures was previously studied only in rats, we extended this investigation to mice injected with kainic acid, because this model involves the activation of ICE/caspase-1 [9]. We found that the systemic administration of VX-765 significantly reduces both acute seizures and spontaneous epileptic activity. This anticonvulsant effect was associated with inhibition of astrocytic IL- $1 \beta$ expression in the hippocampus, whereas glial cell activation was not significantly modified. The use of this anti-inflammatory strategy may be envisaged for treating established pharmacoresistant epileptic conditions.

\section{MATERIALS AND METHODS}

\section{Experimental animals}

Male C57BL6 mice (60 days old, 25 g; Charles River, Calco, Italy) were housed at a constant temperature $\left(23^{\circ} \mathrm{C}\right)$ and relative humidity $(60 \%)$ with free access to food and water and a fixed 12-h light/dark cycle. Procedures involving animals and their care were conducted in accordance with the ethically approved institutional guidelines that are in compliance with national and international laws and policies (EEC Council Directive 86/609, OJ L 358, 1, Dec.12, 1987; Guide for the Care and Use of Laboratory Animals, United States National Research Council, 1996).

\section{Mouse model of acute seizures}

Mice were surgically implanted with an injection guide cannula and recording electrodes under deep Equithesin anesthesia and stereotaxic guidance [11, 25]. Two Nichrome-insulated bipolar depth electrodes $(60 \mu \mathrm{m}$ OD; MOR Electric Heating Assoc. Inc, Comstock Park, MI) were implanted bilaterally into the dorsal hippocampus (from bregma [mm]: nose bar 0 ; anteroposterior, -1.8 ; lateral, \pm 1.5 ; and 2.0 , below dura mater). A $23-$ gauge cannula was unilaterally positioned on top of the dura mater and glued to one of the depth electrodes for the intrahippocampal infusion of kainic acid ("for more detail see as follows"). The electrodes were connected to a multipin socket, and together with the cannula of injection they were secured to the skull by acrylic dental cement. The correct position of the electrodes and injection needle was evaluated by histological analysis of brain tissue at the end of the experiments ("for more detail see as follows").

Intrahippocampal injection of kainic acid in freely moving mice was done 7 days after surgery as previously described $[11,25]$. Kainic acid $(7 \mathrm{ng}$ in $0.5 \mu \mathrm{l}$; Sigma, Saint Louis, MO) was dissolved in $0.1 \mathrm{M}$ phosphate-buffered solution (PBS, $\mathrm{pH}$ 7.4) and injected unilaterally in the dorsal hippocampus by using a needle protruding $2.0 \mathrm{~mm}$ from the bottom of the guide cannula. This dose of kainic acid was proven to induce electroencephalographic (EEG) ictal episodes in the hippocampus in $100 \%$ of mice without mortality $[11,25]$. Selective cell loss in CA3 region of the injected hippocampus is observed 3 to 7 days after kainate injection $[9,11,26]$.

\section{Acute seizures assessment and quantification}

EEG seizures induced by intrahippocampal injection of kainic acid in mice have been extensively described before $[11,25,26]$. Briefly, a 30-minute recording was done before kainic acid injection to assess the basal EEG pattern (FIG. 1a), and for 180 minutes after kainate injection. Kainate was injected for 1 minute CMA/100 pump (CMA microdialysis AB, Solma, Sweden) using a 30-gauge injection needle connected to a $10.0 \mu \mathrm{l}$ Hamilton microsyringe via PE20 tubing; the needle was left in place for 1 additional minute to avoid backflow through the cannula. Ictal episodes (FIG. 1b, d) are characterized by high frequency $(7-10 \mathrm{~Hz})$ and/or multispike complexes, and/or high-voltage $(700 \mu \mathrm{V}-1.0 \mathrm{mV})$ synchronized spikes simultaneously occurring in the injected and contralateral hippocampi. The EEG recording of each animal was analyzed visually to detect any activity different from baseline. Seizure activity was

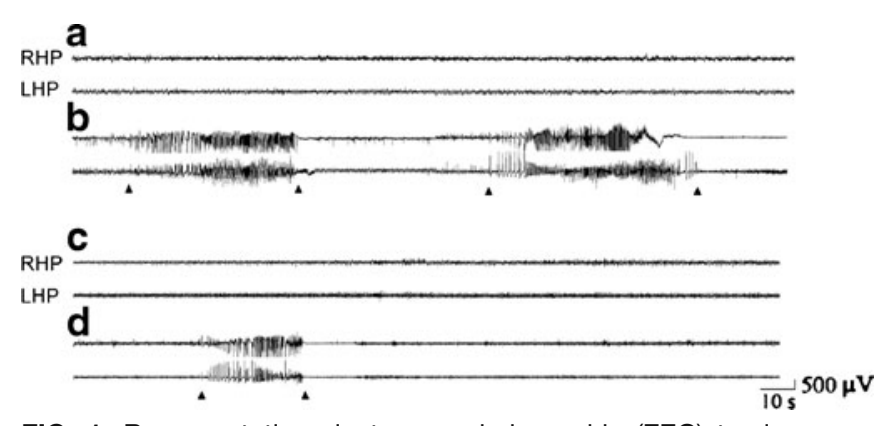

FIG. 1. Representative electroencephalographic (EEG) tracings of acute seizures induced by intra-hippocampal kainate in vehicle- or VX-765-treated mice. Tracings in (a) and (c) depict baseline EEG activity recorded in the left hippocampi (LHP) and right hippocampi (RHP) before kainate injection in the LHP (7 $\mathrm{ng}$ in $0.5 \mu \mathrm{l})$. Tracings in (b) and (d) depict kainate-induced seizure activity (delimited by arrowheads) in mice pretreated with vehicle or $200 \mathrm{mg} / \mathrm{kg}$ i.p. VX-765, respectively. VX-765 reduced seizure number and duration as reported in Table 2. 
quantified by reckoning the time elapsed from kainic acid injection to the occurrence of the first EEG seizure (onset) and the total number and total duration of seizures (reckoned by summing up the duration of every ictal episode during the EEG recording period). Seizures occurred with an average latency of $\sim 10$ minutes from kainic acid injection, and then recurred for $\sim 90$ minutes from their onset, which were associated with motor arrest of the mice.

\section{Chronic epileptic mice}

We used a chronic model of spontaneous epileptic activity that has been extensively described before [23-25, 27-29], which develops in mice following nonconvulsive status epilepticus (SE) lasting for as long as $10 \mathrm{~h}$, induced by unilateral intrahippocampal application of $200 \mathrm{ng}$ in $50 \mathrm{nl}$ kainic acid. Spontaneous epileptic activity reproducibly occurs after 3 to 7 days on average from SE induction ("for more detail see as follows") and it recurs for several months. Once established, this activity is not associated with motor convulsions, it is stable, and it is refractory to phenytoin, carbamazepine, and valproate [24], thus providing a model for focal epilepsy not responding to some commonly used AEDs [24, 25, 27-29]. Histopathological changes are restricted to the hippocampus injected with kainate and are similar to those described in human mesial TLE including neuronal loss, granule cell dispersion, and sprouting [23-25, 27-29].

\section{Status epilepticus induction}

Mice were deeply anesthetized with Equithesin and stereotaxically injected with kainic acid (200 ng in $50 \mathrm{nl}$ phosphate-buffered saline; PBS, pH 7.4; SigmaAldrich) unilaterally into the left dorsal hippocampus at the following coordinates from bregma: $\mathrm{mm}$, nose bar, 0 ; anteroposterior, -1.8 ; lateral, +1.7 ; and 1.9 , below dura [30]. Kainate was injected over $1 \mathrm{~min}(\mathrm{CMA} / 100$ pump) using a 30-gauge injection needle connected to a $0.5 \mu$ l Hamilton microsyringe via PE20 tubing. At the end of the injection, the needle was left in situ for an additional 2 minutes to limit backflow along the injection track. After kainate injection, mice were implanted with two nichrome-insulated bipolar depth electrodes $(60 \mu \mathrm{m}$ OD) bilaterally into the dorsal hippocampus (from bregma $[\mathrm{mm}]$ : nose bar 0 ; anteroposterior -1.8 , lateral \pm 1.7 and 1.9 below dura mater). The electrodes were connected to a multipin socket and secured to the skull by acrylic dental cement. After the mice awoke from anesthesia (i.e., 60 minutes on average), they underwent continuous EEG analysis for $24 \mathrm{~h}$ to determine the occurrence of SE, as defined by high amplitude, uninterrupted spiking activity with an average frequency of 12 to $18 \mathrm{~Hz}$ lasting for at least $3 \mathrm{~h}$. Then the mice were returned to their cages for 6 weeks until EEG recording of spontaneous epileptic activity was initiated. One additional group of control mice $(n=5)$ was injected with PBS, implanted under the same conditions, and used for immunohistochemical analysis ("for more detail see as follows").

\section{Spontaneous epileptic activity}

Six weeks after intrahippocampal kainate injection, mice were EEG monitored to establish their baseline hippocampal activity. EEG was monitored for 3 consecutive days from 9:00 $\mathrm{AM}$ to 11:00 $\mathrm{AM}$ and from 4:00 PM to 6:00 PM. These recordings provided a daily average sampling of epileptic events and their duration in each mouse, within the day-time interval of our pharmacological experiments. This protocol allowed us to select 21 of 23 mice with stable spontaneous epileptic activity before starting the treatment (Table 1). Chronic epileptic activity (FIG. 2) was defined by the appearance and recurrence of subclinical paroxystic events such as: highvoltage sharp waves (HVSW) (1-4 mV; 3-8 Hz; average duration, 20 seconds; FIG. 2 panels a, $a_{1}$ ), which are most commonly observed in groups, and they are usually unilateral, but they may also occur bilaterally; and hippocampal paroxysmal discharges (HPD) that typically start with large amplitude sharp waves $(1-3 \mathrm{mV} ; 1-3 \mathrm{~Hz}$; FIG. 2 panels $b, b_{1}$ ) followed by a train of spikes of increasing frequency $\left(0.5-1.0 \mathrm{mV} ; 10-20 \mathrm{~Hz}\right.$, panel $\left.\mathrm{b}, \mathrm{b}_{2}\right)$ and terminating with a deflection in the EEG (FIG. 2 panels $b, b_{3}$ ). HPDs last 30 to 60 seconds on average, occuring unilaterally (i.e., in the hippocampus originally injected with kainate), and are typically followed by isolated spikes; HPDs represent $\sim 35 \%$ of chronic paroxysmal activity. Sporadic bilateral hippocampal paroxysmal discharges may also occur (FIG. 2 panel d), but these are rare events that were not considered in evaluating drug effects. Spontaneous epileptic activity was quantified by summing up the duration of the previously described events (HVSW and HPD) during a 2-h EEG recording period in the morning (9:00-11:00 AM) and afternoon (4:00-6:00 PM) sessions. HVSW and HPD did not occur during SE and epileptogenesis, although they were always observed in the chronic phase and were stable and reproducible in each epileptic mouse.

Isolated spikes or spike trains with a frequency of 1 to $3 \mathrm{~Hz}$, and/or duration less than 20 seconds (FIG. 2 panel c) were not considered in the quantitative analysis of epileptic activity.

EEG activity was monitored using the GRASS 79D EEG recording system (Astro-Med Industrial Park, West Warwick, RI), the signal was digitalized with a PowerLab 16/S data acquisition system (ADInstrument Pty. Ltd., Bella Vista, NSW, Australia) and analyzed with LabChart 7 software (ADInstrument Pty. LTD, Bella Vista NSW, Australia).

EEG analysis in acute and chronic models was done by two independent investigators blinded to the treat- 
Table 1. Baseline Spontaneous Epileptiform Activity Assessed by EEG Analysis in Chronic Epileptic Mice used for Pharmacological Experiments

\begin{tabular}{|c|c|c|c|c|c|c|}
\hline \multirow[t]{4}{*}{ Mouse I.D. } & \multicolumn{6}{|c|}{ Time in Epileptic Activity (min) } \\
\hline & \multicolumn{6}{|c|}{ Days } \\
\hline & 1 & 2 & 3 & 1 & 2 & 3 \\
\hline & \multicolumn{3}{|c|}{ 9:00-11:00 AM } & \multicolumn{3}{|c|}{ 4:00-6:00 PM } \\
\hline 1 & 44.2 & 38.9 & 25.0 & 33.2 & 35.7 & 35.6 \\
\hline 2 & 32.1 & 32.4 & 34.6 & 39.7 & 36.8 & 35.3 \\
\hline 3 & 38.7 & 41.0 & 32.1 & 29.3 & 36.1 & 37.3 \\
\hline 4 & 19.8 & 11.6 & 14.5 & 19.5 & 10.8 & 14.8 \\
\hline 5 & 33.0 & 37.5 & 33.4 & 38.1 & 32.1 & 38.0 \\
\hline 6 & 42.2 & 30.2 & 34.1 & 27.0 & 32.1 & 26.0 \\
\hline 7 & 38.2 & 32.3 & 35.3 & 51.1 & 34.2 & 33.2 \\
\hline 8 & 66.0 & 66.3 & 60.2 & 63.2 & 60.3 & 63.1 \\
\hline 9 & 11.1 & 12.3 & 14.0 & 17.2 & 13.2 & 12.4 \\
\hline 10 & 35.1 & 30.8 & 31.3 & 29.4 & 33.6 & 31.0 \\
\hline 11 & 35.0 & 30.8 & 31.2 & 28.9 & 30.2 & 29.5 \\
\hline 12 & 40.8 & 36.8 & 33.0 & 32.1 & 31.4 & 28.5 \\
\hline 13 & 15.0 & 18.4 & 14.3 & 22.1 & 20.9 & 16.4 \\
\hline 14 & 25.6 & 20.1 & 18.1 & 23.1 & 29.4 & 28.6 \\
\hline 15 & 39.5 & 36.3 & 36.1 & 30.2 & 35.0 & 28.4 \\
\hline 16 & 36.8 & 40.4 & 33.2 & 32.0 & 31.3 & 30.4 \\
\hline 17 & 30.7 & 25.3 & 25.1 & 26.0 & 18.9 & 26.1 \\
\hline 18 & 25.1 & 29.6 & 27.9 & 24.9 & 32.7 & 31.4 \\
\hline 19 & 27.0 & 30.9 & 29.7 & 28.9 & 29.7 & 27.9 \\
\hline 20 & 28.8 & 26.2 & 29.5 & 28.6 & 25.6 & 26.6 \\
\hline 21 & 43.1 & 37.8 & 40.1 & 42.7 & 39.6 & 44.5 \\
\hline
\end{tabular}

Mice were used as follows: numbers 1 to 9 were injected with $200 \mathrm{mg} / \mathrm{kg}$ VX-765; numbers 10 to 15 were injected with $50 \mathrm{mg} / \mathrm{kg}$ VX-765; numbers 16 to 21 were injected with $12.5 \mathrm{mg} / \mathrm{kg}$ VX-765. Mice numbers 5 to 9 were also treated with $50 \mathrm{mg} / \mathrm{kg}$ phenytoin before VX-765; mice numbers 10 to 15 were also treated with $3 \mathrm{mg} / \mathrm{kg}$ dexamethasone after treatment with $50 \mathrm{mg} / \mathrm{kg} \mathrm{VX}-765$. ("For details on treatment protocols see Methods and FIG. 3.").

$\mathrm{EEG}=$ electroencephalographic; I.D. = identification.

ment, who visually reviewed all the EEG tracings. Deviation of $\leq 5 \%$ from concordance was considered acceptable; otherwise, EEG tracing was additionally analyzed by a third person.

\section{Pharmacological treatments}

Mouse model of acute seizures. A total number of 46 mice were used in these experiments. VX-765 (Vertex Pharmaceuticals Inc.), which dissolved in $0.1 \%$ Tween 80 in $0.5 \%$ hydroxy-ethyl-cellulose in distilled water was injected at $12.5,50,100$, and $200 \mathrm{mg} / \mathrm{kg}$ i.p. in different groups of mice daily (i.e., at 9:00 AM) for 3 consecutive days, and on day 4 a bolus injection was done 45 minutes before kainic acid application. This repeated treatment regimen using $200 \mathrm{mg} / \mathrm{kg}$ VX-765 was previously shown to provide brain concentrations of VRT-043198 (the active metabolite of VX$765)$ able to block enzyme activity $(70-140 \mathrm{nM}$, measured $2 \mathrm{~h}$ after the last drug administration), and showed anticonvulsant effects on acute seizures induced in rats by kainic acid [9] and in rapid kindling [12]. An EEG recording was made for $3 \mathrm{~h}$ after kainic acid administration ("for more details see previous information"); a 30-minute EEG recording similar to baseline was required in each mouse before ending the experiment.
Chronic epileptic mice. We used a total number of 21 epileptic mice and randomly divided them into 3 experimental groups to be treated with $12.5 \mathrm{mg} / \mathrm{kg}$ i.p. $(n=6), 50 \mathrm{mg} / \mathrm{kg}$ i.p. $(n=6)$, or $200 \mathrm{mg} / \mathrm{kg}$ i.p. $(n=9) \mathrm{VX}-$ 765. We chose this study design to be able to test the anticonvulsant effect of the different drug doses on chronic epileptic activity at approximately the same time (i.e., $\sim 6$ weeks) after SE induction in mice. The larger number of mice in the group treated with $200 \mathrm{mg} / \mathrm{kg}$ VX-765 dose was required by the post-hoc immunohistochemical analysis ("for details see as follows").

Among the 9 epileptic mice to be treated with $200 \mathrm{mg} / \mathrm{kg}$ VX-765, we randomly chose 5 mice (Table 1 , numbers 5-9) to confirm previous literature evidence that chronic epileptic activity in this model was unaffected by some conventional AEDs [24]. This group of 5 epileptic mice was treated with a single dose of $50 \mathrm{mg} / \mathrm{kg}$ phenytoin i.p., 7 days before starting $200 \mathrm{mg} / \mathrm{kg}$ VX-765 treatment (protocol is shown in FIG. 3 panel a). This dose of phenytoin was previously shown to reduce acute or spontaneous seizures in rodents within $2 \mathrm{~h}$ after a single drug administration [31, 32].

For each VX-765 dose regimen, the following treatment protocol was adopted in each epileptic mouse 
High voltage sharp waves

a

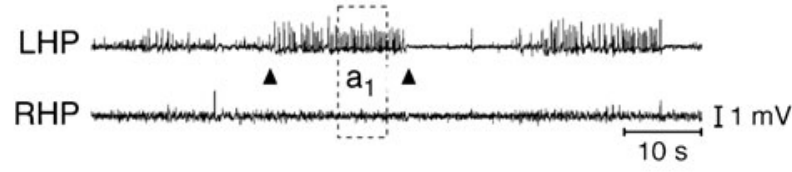

$a_{1}$

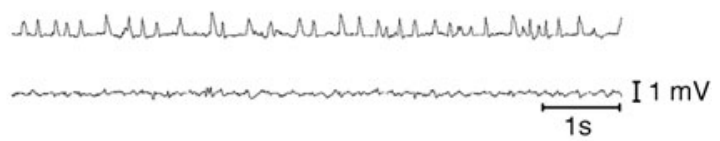

Unilateral hippocampal paroxysmal discharges

b

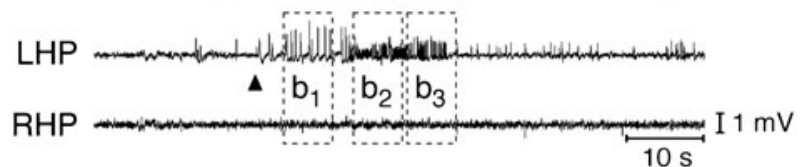

$b_{1}$
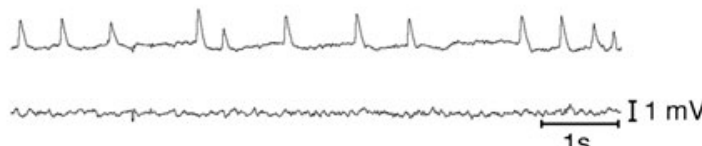

$b_{2}$

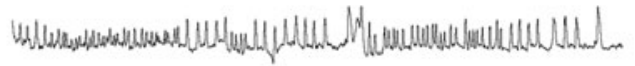

$b_{3}$
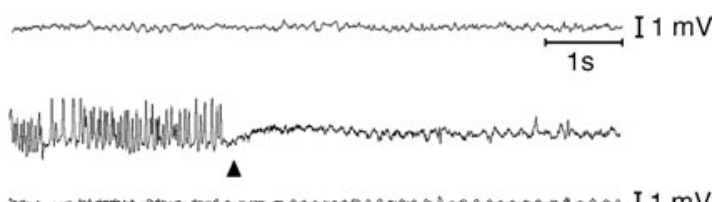

1s

Interictal activity

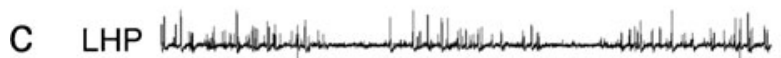

RHP

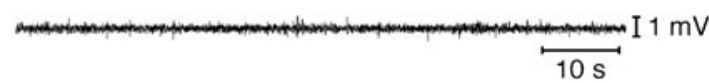

Bilateral hippocampal paroxysmal discharges (sporadic)

d

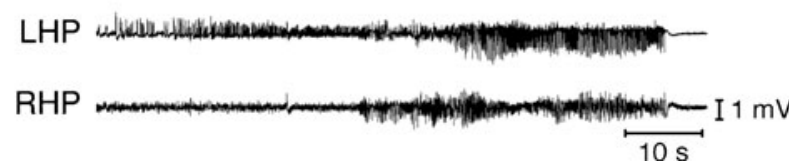

FIG. 2. Representative electroencephalographic (EEG) tracings of chronic epileptic activity induced by intra-hippocampal kainate in mice. Chronic epileptic activity develops in mice 3 to 7 days after unilateral intra-hippocampal injection (left hippocampus [LHP]) of kainate (200 ng in $50 \mathrm{nl}$ ) causing SE. Tracings in (a) (boxed area is enlarged in $a_{1}$ ) and (b) (boxed areas are enlarged in $b_{1}, b_{2}, b_{3}$ ) depicting high-voltage sharp waves (HVSW) $(1-4 \mathrm{mV}$; $3-8 \mathrm{~Hz}$; average duration, 20 seconds) and unilateral hippocampal paroxysmal discharges (HPDs) that typically start (arrowhead in panel b) with large amplitude sharp waves (1-3 mV; 1-3 Hz; panel b1) followed by a train of spikes of increasing frequency $(0.5-1.0 \mathrm{mV} ; 10-20 \mathrm{~Hz}$, panels $b_{2}, b_{3}$ ), and terminating with a deflection in the EEG (arrowhead in panel $b_{3}$ ). HVSW and HPDs were inhibited by VX-765 administration (see FIG. 4b-d). Panel (c) depicts interictal activity consisting of isolated spikes or spike trains (1-3 Hz; duration, <20 seconds); panel (d) shows bilateral hippocampal paroxysmal discharges (sporadic events in this model). The events in panels (c) and (d) were not included in the quantification of chronic epileptic activity. $\mathrm{RHP}=$ right hippocampus.
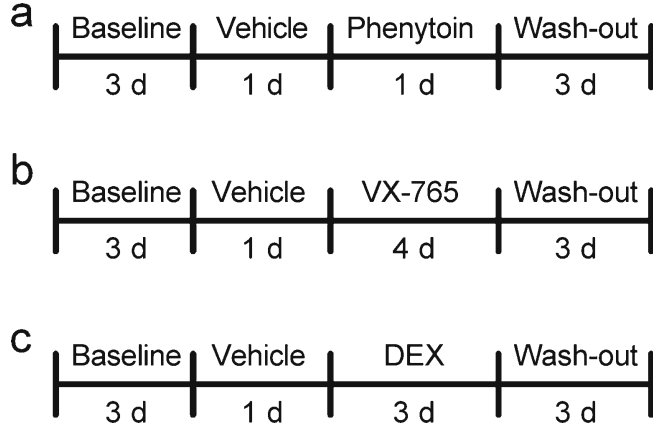

FIG. 3. Schematic representation of the treatment protocols in chronic epileptic mice. Panel (a) depicts the treatment protocol used in 5 randomly chosen epileptic mice: after establishing the baseline of spontaneous epileptic activity, the mice were treated intraperitoneally with a single dose of $50 \mathrm{mg} / \mathrm{kg}$ phenytoin. Then they underwent a 3-day wash-out period before entering protocol (b) $(200 \mathrm{mg} / \mathrm{kg} \mathrm{VX-765).} \mathrm{Panel} \mathrm{(b)} \mathrm{depicts} \mathrm{the} \mathrm{treatment} \mathrm{pro-}$ tocol of 21 epileptic mice with VX-765: 3 days of electroencephalographic (EEG) baseline recording was done, and on day 4 , the vehicle of VX-765 was injected intraperitoneally twice (at 9:00 AM and 4:00 PM), and on the following day, the epileptic mice received VX-765 twice a day (at 9:00 AM and 4:00 PM) for 4 consecutive days, and the EEG recording was done for $2 \mathrm{~h}$ after each drug administration. The last drug administration was followed by a 3-day wash-out period, and each day EEG was recorded (at 9:00 AM to 11:00 AM) to evaluate the time required by each epileptic mouse to recover its pre-injection baseline activity after drug withdrawal. Mice injected with VX-765 were killed for histological analysis (i.e., 5 mice at the time of maximal drug effect and 4 mice after drug wash-out). Panel (c) depicts the treatment protocol with dexamethasone: 6 epileptic mice at the end

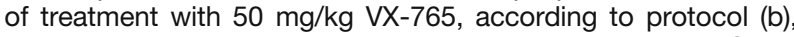
including the 3-day wash-out period were recorded by EEG continuously (between 9:00 AM and 5:00PM) for 3 additional days (days $1-3$ ) to monitor if the baseline epileptic activity had resumed and was stable. Then the vehicle was subcutaneously injected on day 4 (at 9:00 AM and 4:00 PM); on day 5, the baseline was again recorded (between 9:00 AM and 11:00 AM), followed by a subcutaneous injection of dexamethasone in alcohol formulation $(3 \mathrm{mg} / \mathrm{kg})$. An EEG recording was continued for an additional $6 \mathrm{~h}$ (i.e., until 5:00PM). This procedure was repeated for 3 consecutive days. A 3-day wash-out period followed the last dexamethasone dose. $d=$ day; $D E X=$ dexamethasone.

(FIG. 3 panel b): after 3 days of EEG baseline recording, on day 4 of the vehicle of VX-765 was intraperitoneally injected twice (9:00 $\mathrm{AM}$ and 4:00 PM), and no changes in baseline were observed (not shown). Then epileptic mice received VX-765 twice a day (9:00 AM and 4:00 PM) for 4 consecutive days, and EEG recording was done for $2 \mathrm{~h}$ after each drug administration since this drug was proven to be effective for at least $2 \mathrm{~h}$ in the acute seizure model [9]. The last drug administration was followed by a 3-day wash-out period during which EEG was recorded daily from 9:00 am to $11: 00 \mathrm{am}$; the time required by each epileptic mouse to recover its pre-injection baseline activity after drug withdrawal (after day 4 of treatment, i.e., the eighth drug administration) was used to estimate the duration of VX-765 anticonvulsant action.

At the end of the pharmacological experiments with $50 \mathrm{mg} / \mathrm{kg} \mathrm{VX}-765$ (including the 3 day wash-out period), the epileptic mice (Table 1, numbers 10-15) were recorded continuously between 9:00 $\mathrm{AM}$ and 5:00 PM for 
3 additional days (days 1-3) to monitor if baseline EEG epileptic activity was resumed and stable. Then the vehicle of dexamethasone (DEX) was injected subcutaneously on day 4 (9:00 $\mathrm{AM}$ and 4:00 PM), and again no changes in baseline were observed (not shown). Baseline was again recorded in each mouse on day 5 between 9:00 $\mathrm{AM}$ and 11:00 AM, followed by a subcutaneous injection of $3 \mathrm{mg} / \mathrm{kg}$ DEX in alcohol formulation [33] and an EEG recording that was continued for an additional $6 \mathrm{~h}$ (i.e., until 5:00 PM). This procedure was repeated for 3 consecutive days (see the protocol in FIG. 3 panel c).

\section{Immunocytochemistry}

We studied IL-1 $\beta$ expression, glia activation, and leukocytes (granulocytes, T-lymphocytes, and macrophages) extravasation in the hippocampus of epileptic mice treated with $200 \mathrm{mg} / \mathrm{kg} \mathrm{VX-765} \mathrm{and} \mathrm{killed}$ randomly, either at the end of drug wash-out (when spontaneous epileptic activity had resumed, i.e., day 10 in FIG. $4 \mathrm{c} ; n=4)$ or at the time of maximal anticonvulsant effect (day 7 in FIG. 4c; $n=5$ ).

Mice were deeply anesthetized using Equithesin and perfused via ascending aorta with $50 \mathrm{mM}$ cold PBS (pH 7.4), followed by chilled $4 \%$ paraformaldehyde in $0.1 \mathrm{M}$ PBS. The brains were post-fixed for 90 minutes at $4^{\circ} \mathrm{C}$, and were then transferred to $20 \%$ sucrose in PBS for $24 \mathrm{~h}$ at $4^{\circ} \mathrm{C}$. The brains were rapidly frozen in $-50^{\circ} \mathrm{C}$ isopentane for 3 minutes and stored at $-80^{\circ} \mathrm{C}$ until assayed. Serial cryostat coronal sections $(40 \mu \mathrm{m})$ were cut from all brains throughout the septotemporal extension of the hippocampus [30] and were collected in $0.1 \mathrm{M}$ PBS. Four series of 9 adjacent slices were used, with 1 slice for each marker: first, second, third, seventh, eighth, and ninth slices, respectively, were used for IL$1 \beta$, glial-fibrillary acidic protein (GFAP), CD11b, granulocyte (Gr-1), macrophages (CD68), and T-lymphocytes (CD3); the fourth and fifth slices were used for double immunostaining; and the sixth slice was used for Nissl staining. Primary and secondary antibodies and experimental procedures were those previously shown to determine a specific immunohistochemical signal of the protein of interest in rodent brain slices [10, 25, 34]. For IL-1 $\beta$ or glia markers (GFAP, CD11b), slices were incubated at $4{ }^{\circ} \mathrm{C}$ for 10 minutes in $70 \%$ methanol and $2 \%$ $\mathrm{H}_{2} \mathrm{O}_{2}$ in Tris HCl-buffered saline (TBS, $\mathrm{pH}$ 7.4), followed by 30 -minute incubation in $10 \%$ in fetal calf serum in $1 \%$ (for IL-1 $\beta$ ) or $0.1 \%$ (for glia markers) Triton X-100 in TBS. Then slices were incubated overnight with the primary antibody to IL-1 $\beta$ (1:200; Santa Cruz Biotechnology), to mouse GFAP (1:2500; Chemicon), a selective marker of astrocytes, or to mouse CD11b (1:1000; MAC-1, Serotec), a marker of monocyte/microglia cells, at $4^{\circ} \mathrm{C}$ in $10 \%$ fetal calf serum in 1\% Triton X-100 in TBS. For macrophages, granulocytes, and T-lymphocytes, slices were incubated at room temperature for 10 minutes in $1 \% \mathrm{H}_{2} \mathrm{O}_{2}$ in TBS, followed by $1 \mathrm{~h}$ incubation in $10 \%$ normal goat serum in $0.3 \%$ Triton X-100 in TBS. Then slices were incubated overnight with the primary antibody to mouse CD68 (1:200; Serotec), a selective marker of macrophages, human CD3 (1:150; Dako), a selective marker of T-lymphocytes, or mouse granulocyte-differentiation antigen 1 (1:50; Gr-1; BD Pharmingen), a marker of granulocytes, at $4{ }^{\circ} \mathrm{C}$ in $4 \%$ normal goat serum in $0.1 \%$ Triton X-100 in TBS.

Immunoreactivity was tested by the avidin-biotin-peroxidase technique (Vector Labs, INC, Burlingame, CA); the sections were reacted using diaminobenzidine, and the signal was amplified by nickel ammonium only for IL-1 $\beta$. No immunostaining was observed by incubating the slices with the primary antibodies pre-absorbed with the corresponding peptides, or without the primary antibodies [10, 25, 34].

\section{Double-immunostaining}

After incubation with the primary IL-1 $\beta$ antibody, slices were incubated in biotinylated secondary anti-goat antibody (1:200, Vector Labs), then in streptavidin-horseradish peroxidase (HRP) and the signal was revealed with tyramide conjugated to fluorescein using the TSA amplification kit (NEN Life Science Products, Boston, MA). Sections were subsequently incubated with the following primary antibodies: mouse anti-GFAP $(1: 2500)$ or rat antimouse CD11b (1:1000). Fluorescence was detected using anti-mouse or anti-rat secondary antibody conjugated with Alexa546 (Molecular Probes, Leiden, The Netherlands). Slide-mounted sections were examined with an Olympus Fluorview laser scanning confocal microscope (microscope BX61 and confocal system FV500; Hamburg, Germany) using dual excitation of $488 \mathrm{~nm}$ (Laser Ar) and $546 \mathrm{~nm}$ (Laser He-Ne green) for fluorescein and Alexa546, respectively. The emission of fluorescent probes was collected on separate detectors. To eliminate the possibility of bleed through between channels, the sections were scanned in a sequential mode.

\section{Statistical analysis of data}

Data are the mean \pm standard error of the mean ( $n=$ number of individual samples). The effects of treatments were analyzed by Graph-Pad software (Graph Pad Software Inc., La Jolla, CA) using absolute values. The effects of treatment were analyzed by one-way analysis of variance or by repeated measures of analysis of variance followed by Tukey's test using raw data. Differences due to the treatments were considered significant with a $P<0.05$.

\section{RESULTS}

\section{Anticonvulsant activity of VX-765}

Table 2 shows the dose-response effect of VX-765 in the mouse model of acute seizures induced by intrahippocampal injection of kainic acid. FIG. 1 depicts 

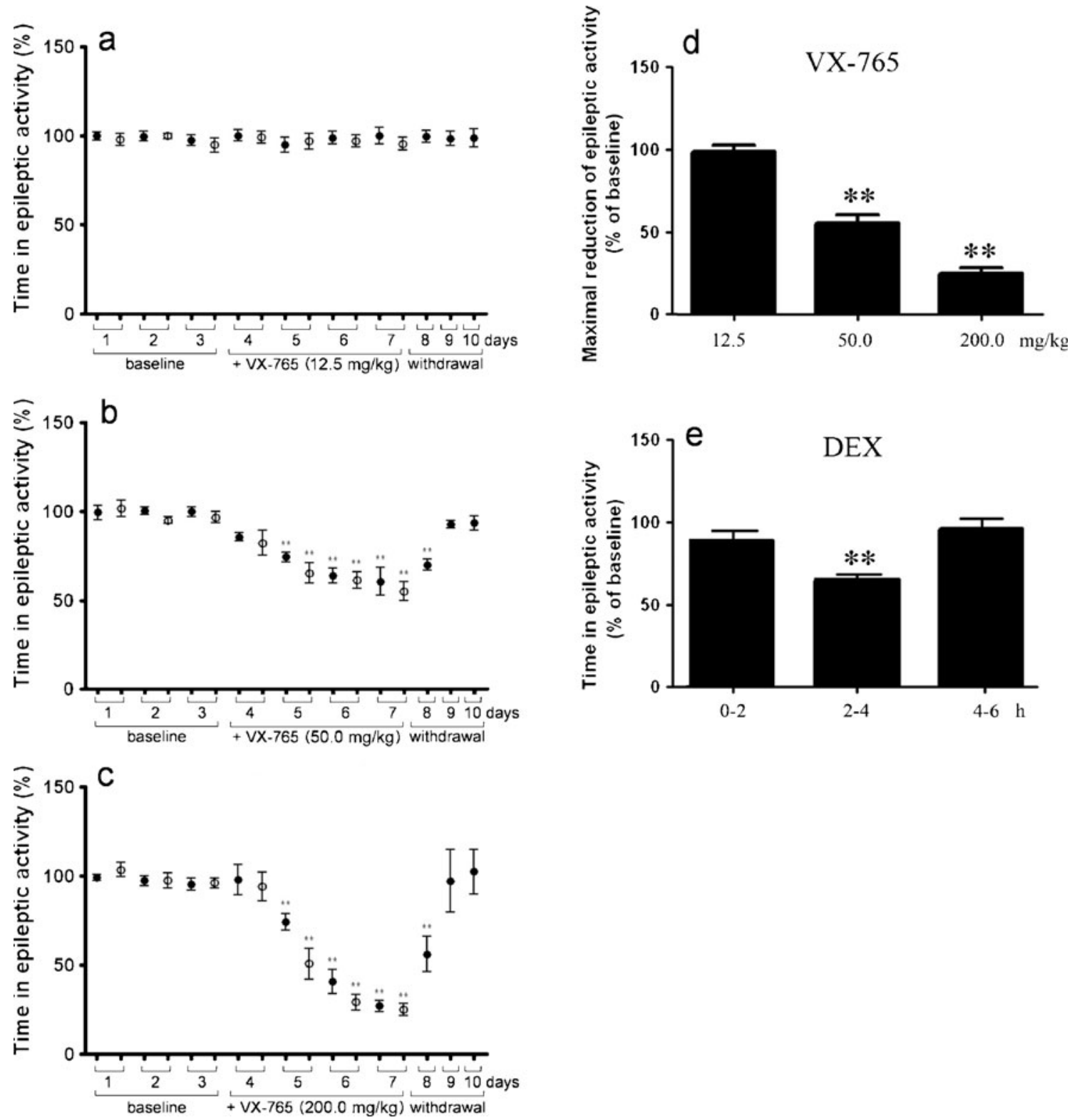

FIG. 4. Panels $(a-c)$ : Anticonvulsant effects of $V X-765$ and dexamethasone in chronic epileptic mice. Electroencephalographic (EEG) activity was recorded and quantified for 3 days (days 1-3) in C57BL/6 epileptic mice, 6 weeks after kainate-induced status epilepticus (200 ng in $50 \mathrm{nl}$ ). Mice $(n=21)$ with a stable baseline of spontaneous epileptic activity (days 1-3; "see Table 1 for row values") were injected daily intraperitoneally with $12.5(n=6), 50(n=6)$, or $200 \mathrm{mg} / \mathrm{kg} \mathrm{VX-765} \mathrm{(n=9)} \mathrm{(twice} \mathrm{a} \mathrm{day} \mathrm{at} \mathrm{9:00AM} \mathrm{and} \mathrm{at} \mathrm{4:00PM)} \mathrm{from} \mathrm{day} 4$ to day 7 ("see Methods for details") (panels a-c). EEG activity was measured continuously after each drug injection for $2 \mathrm{~h}$, then discontinued until the subsequent injection. In each experimental group, VX-765 treatment was withdrawn at day 7 (after the 4:00PM injection), and EEG recordings were made for the subsequent 3 days (days 8-10) to monitor when pre-injection baseline was resumed after drug wash-out. Panel (d) depicts the maximal reduction in epileptic activity, as assessed for each dose of VX-765 at day 7 (after the 4:00PM injection). Panel (e) shows data from a subgroup of epileptic mice $(n=6)$ treated with dexamethasone ( $3 \mathrm{mg} / \mathrm{kg} \mathrm{s.c.)} \mathrm{for} 3$ days ("see Methods and FIG. 3c"). Data from day 1 of treatment only are shown because the same effect was observed in the subsequent 2 days. Data in panels $(\mathrm{a}-\mathrm{e})$ are presented as mean \pm standard error of the mean of epileptic activity, expressed as a percentage of the corresponding pre-injection baseline (baseline raw data are shown in Table 1). ${ }^{*} p<0.05 ;{ }^{* *} p<0.01$ versus baseline by repeated measures analysis of variance followed by Dunnett's test. DEX=dexamethasone.

representative EEG tracings from kainate-injected mice treated with vehicle (FIG. 1a, b) or $200 \mathrm{mg} / \mathrm{kg}$ VX-765 injected mice (FIG. 1c, d). An average 50\% and 64\% decrease in the number of seizures and their total duration was observed with 50 to $200 \mathrm{mg} / \mathrm{kg} \mathrm{VX-765} \mathrm{(Table} \mathrm{2).} \mathrm{The}$ time to onset of the first seizure was significantly delayed at doses of 100 and $200 \mathrm{mg} / \mathrm{kg}$. No effects of $12.5 \mathrm{mg} / \mathrm{kg}$ on seizure parameters were observed (Table 2).

Table 1 reports the quantification of time spent in spontaneous epileptic activity in each mouse used for pharmacological evaluation of VX-765 effect. In the 2-h EEG recording during the morning and afternoon 
Table 2. Dose-Response Effect of VX-765 on Acute Seizures

\begin{tabular}{lcccc}
\hline & Dose $(\mathrm{mg} / \mathrm{kg})$ & Onset time (minutes) & Number of seizures & Time in seizures (minutes) \\
\hline Vehicle & - & $8.4 \pm 0.9$ & $14.0 \pm 1.0$ & $12.0 \pm 1.0$ \\
VX-765 & 12.5 & $6.7 \pm 0.7$ & $13.0 \pm 3.0$ & $8.8 \pm 1.7$ \\
& 50.0 & $10.2 \pm 1.5$ & $8.0 \pm 1.0^{*}$ & $6.4 \pm 1.4^{\dagger}$ \\
& 100.0 & $18.1 \pm 2.2^{\dagger}$ & $6.0 \pm 1.0^{\dagger}$ & $5.0 \pm 1.4^{\dagger}$ \\
& 200.0 & $19.8 \pm 4.1^{\dagger}$ & $6.0 \pm 1.0^{\dagger}$ & $3.7 \pm 0.8^{\dagger}$ \\
\hline
\end{tabular}

VX-765 $(12.5,50,100,200 \mathrm{mg} / \mathrm{kg})$ was injected intraperitoneally once a day for 3 consecutive days; on day 4 , the drug was injected 45 minutes before kainic acid. Kainate (7 $\mathrm{ng}$ in $0.5 \mu \mathrm{l})$ was injected unilaterally in the left hippocampus in freely moving C57BL6 mice $(n=7--12)$. $\mathrm{IL}=$ interleukin.

${ }^{*} p<0.05 ;{ }^{\dagger} p<0.01$ versus vehicle-injected mice by one-way analysis of variance followed by Tukey’s post hoc test.

sessions, daily spontaneous epileptic activity ("see representative tracings in FIG. 2 panels a and b") was stable and reproducible in each epileptic mouse (i.e., $\sim 6$ weeks after status epilepticus). FIG. $4 \mathrm{a}-\mathrm{d}$ shows the dose-dependent anticonvulsant effect of VX-765 in the 2-h EEG recordings (i.e., from 9:00 AM to $11: 00 \mathrm{AM}$, and from $4: 00 \mathrm{PM}$ to $6: 00 \mathrm{PM})$ after each daily injection. The systemic administration of VX765 in epileptic mice dose- and time-dependently reduced the time spent in epileptic activity during the 4 days of treatment (FIG. $4 \mathrm{a}-\mathrm{d}$ ): a maximal 50 to $75 \%$ reduction was achieved using 50 and $200 \mathrm{mg} / \mathrm{kg}$, respectively (FIG. 4d) (days 6 and 7 in FIG. 4b, c), as compared to respective pre-injection baselines (days 1-3 in FIG. $4 \mathrm{~b}, \mathrm{c}$ ); a dose of $12.5 \mathrm{mg} / \mathrm{kg}$ was ineffective (FIG. 4a, d). The anticonvulsant effect of VX-765 began on day 2 of treatment (i.e., day 5 in FIG. 4b, c; corresponding to the third and fourth injections). After reaching the maximal anticonvulsant effect $(50$ and $200 \mathrm{mg} / \mathrm{kg}$ at day 7 , the 4:00 PM injection), VX-765 administration was interrupted: seizure activity was still significantly reduced for $15 \mathrm{~h}$ after drug withdrawal (i.e., day 8), and then it recovered to pre-injection baseline within the next $24 \mathrm{~h}$ (day 9 in FIG. 4b, c).

To assess the effect of an anti-inflammatory steroid drug, epileptic mice (Table 1, numbers 10-15) were injected daily with $3 \mathrm{mg} / \mathrm{kg}$ s.c. DEX after 2-h baseline recording; this treatment was repeated for 3 days ("see Methods and FIG. 3c for details"). DEX treatment reduced spontanenous epileptic activity by $30 \%$ on average $(p<0.01)$ between the second and fourth hour after each daily injection. Then mice invariably recovered their pre-injection baseline epileptic activity within the fourth and sixth hour after drug injection (FIG. 4e).

In accordance with Riban et al. [24], $50 \mathrm{mg} / \mathrm{kg}$ phenytoin (Table 1, tested in mice numbers 5-9 ) did not affect spontaneous EEG epileptic activity in the 2-h post-injection period (percentage changes of time in epileptic activity $v s$ respective pre-injection baseline was $110.8 \pm 6.0 \% ; n=5)$.

\section{Histological analysis}

As we previously described in Maroso et al. [25], Nissl-stained sections of the hippocampi of epileptic mice showed unilateral neuronal cell loss reminescent of hippocampal sclerosis, involving pyramidal cell layers and the hilus of the dentate gyrus, and dispersion of granule cells (FIG. 5a-c). In accordance with Riban et al. [24], this pattern was restricted to the KA-injected (kainic acid) side (FIG. 5b) because the contralateral noninjected side (FIG. 5c) had normal histology similar to naïve mice (FIG. 5a) ("for details also see Bouilleret et al. [23], Riban et al. [24], Maroso et al. [25], and Antonucci et al. [27]").

Immunohistochemical analysis of hippocampal sections from epileptic mice after wash-out of VX-765 (FIG. 5e, h) showed activation of GFAP-positive astrocytes (FIG. 5e vs d) and CD11b-positive microglia (FIG. 5h $v s$ g) in kainate injected hippocampi. IL-1 $\beta$ expression was not observed in control mice (FIG. 5j); whereas it was increased in GFAP-positive astrocytes in epileptic mice (FIG. 5k vs j; co-localization in panels FIG. 5k1-k3). No expression of IL-1 $\beta$ in CD11bpositive microglia was found (FIG. 5k inset). A similar glia activation and IL-1 $\beta$ expression pattern were observed in the hippocampus contralateral to kainate injection (not shown).

Epileptic mice treated VX-765 and euthanized at the time of its maximal anticonvulsant effect, showed no IL-1 $\beta$ expression in the hippocampus (FIG. 51 vs k). Although astrocytes did not express IL-1 $\beta$ during VX-765 treatment (FIG. 511-13), the astrocytes still showed activated phenotype (FIG. $5 \mathrm{f} v s$ e and d). Similarly, VX-765 did not alter microglia activation (FIG. $5 \mathrm{i} v \mathrm{~h}$ and $\mathrm{g}$ ).

Scattered perivascular CD68-immunoreactive macrophage-like cells were found near blood vessels in the hippocampi of epileptic mice (FIG. 5h inset), similarly to what was observed in VX-765 treated mice (not shown); these cells were absent in control mice (not shown). Granulocytes and $\mathrm{T}$ cells were not detected in brain parenchyma in all experimental groups (not shown). 

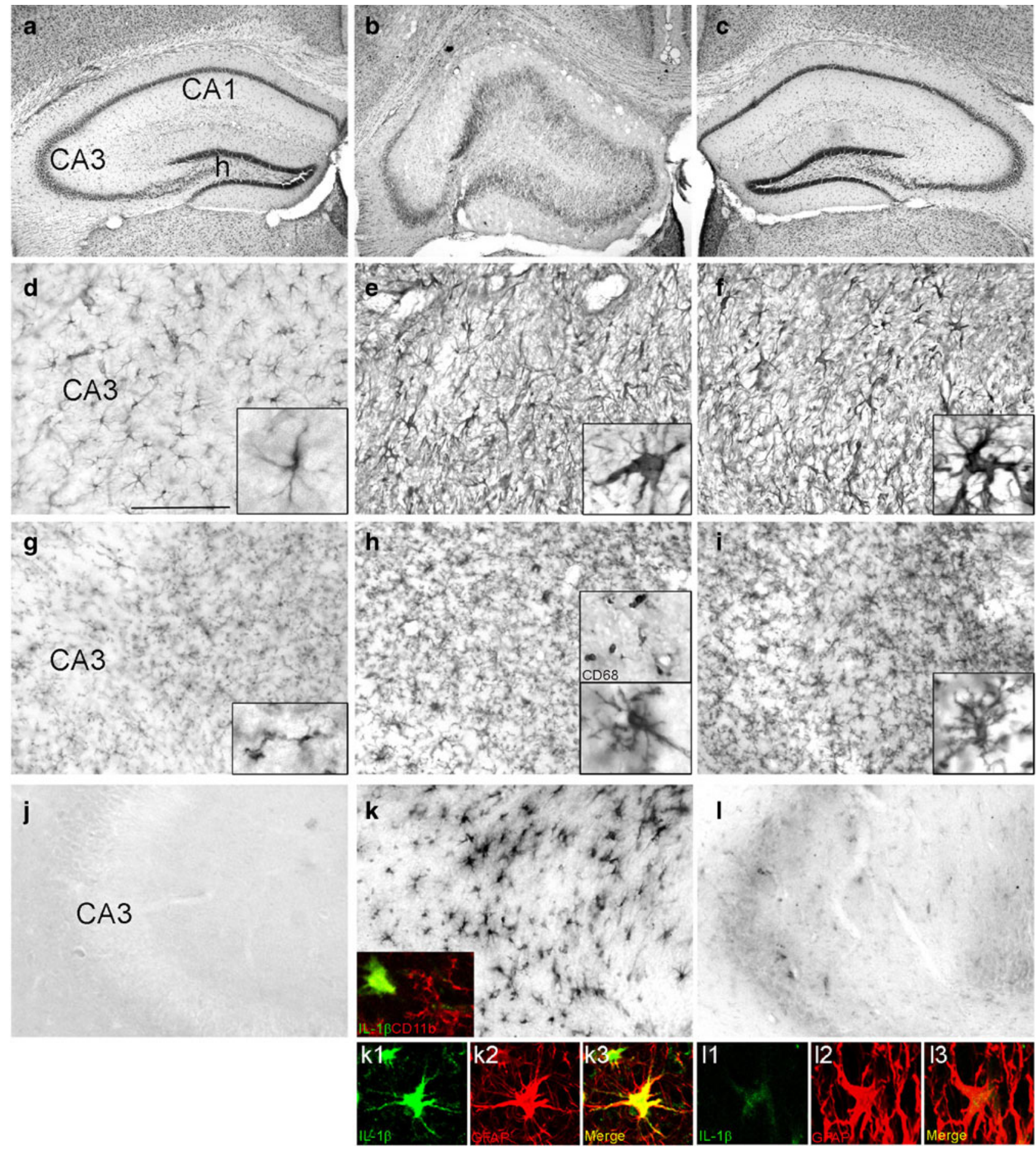

FIG. 5. Histopathology, interleukin (IL)-1 $\beta$ expression, and glia activation in the hippocampus of epileptic mice, and effect of VX-765. Nissl-stained sections of the hippocampi of representative (a) vehicle-injected and (b, c) epileptic mice. (b) The hippocampus injected with kainate shows histopathology reminescent of hippocampal sclerosis, involving cell loss in pyramidal cell layers and degeneration of hilar interneurons, and dispersion of granule cells. (c) The contralateral non-injected side has normal histology similar to (a) vehicleinjected mice. $(d-l)$ These panels show representative micrographs of CA3 hippocampal sections depicting (d-f) GFAP-positive astrocytes, (g-i) CD-11b-positive microglia, and (j-l) IL-1 $\beta$ immunostaining in (d, g, and j) vehicle-injected mice, and (e, f, h, i, k, and I) epileptic mice. (e, h, and k) Show the hippocampus of an epileptic mouse at the end of $200 \mathrm{mg} / \mathrm{kg} \mathrm{VX-765} \mathrm{wash-out} \mathrm{period} \mathrm{(i.e.,} \mathrm{at} \mathrm{day} 10$ in FIG. 4c); (f, i, and I) show the hippocampus of a representative mouse killed at the time of maximal anticonvulsant drug effect (i.e., at day 7 in FIG. 4c). (d-i, insets) show 4-fold magnification of glial cells to show their phenotypic activation in (e, f, h, and i) epileptic tissue vs (d, g) control tissue. ( $h$, inset) shows a 2-fold magnification of perivascular CD68-positive macrophages. Co-localization panels $\left(k_{1}-l_{3}\right)$ show IL-1 $\beta$ expression in activated astrocytes in the hippocampus of epileptic mice; note the inhibition of IL-1 $1 \beta$ expression in VX-765 treated mice $\left(I_{1}-I_{3}\right)$. IL-1 $\beta$ signal did not co-localize with CD11b signal denoting lack of IL-1 $\beta$ localization in microglia (k, inset). Scale bar in (a-C) $250 \mu \mathrm{m}$; (d-l) $100 \mu \mathrm{m}$. CA1=Cornus Ammoni's 1; CA3=Cornus Ammoni's 1; $\mathrm{h}=$ hilus. 


\section{DISCUSSION}

These results show a powerful anticonvulsant effect of VX-765 (a specific inhibitor of ICE/caspase-1) after its systemic administration in a mouse model of acute seizures and in chronic epileptic mice with neuropathological features mimicking TLE with hippocampal sclerosis [2325, 27-29]. As in human TLE, spontaneous epileptiform activity in this mouse model is resistant to some common AEDs [24] (as in the present study). We used spontaneous epileptic activity to assess impact of drugs, rather than spontaneous seizures. This activity is more consistent than spontaneous seizures, which can be erratic, and this approach does not require continuous video EEG monitoring, which would substantially reduce the extent of experiments we could perform. We selected epileptic activity ("for more detail see FIG. 2") that is more consistent with the subclinical seizures seen in humans during intracranial monitoring $[35,36]$, and it is distinct from inter-ictal activity.

Unlike other caspases, ICE/caspase-1 is specifically required for processing the inactive precursor pro-IL- $1 \beta$ to biologically active IL-1 $\beta$ [17], and for its subsequent secretion from the cell. VX-765, which represents a new class of specific ICE/caspase-1 protease inhibitors, is a prodrug with improved oral bioavailability that has been under clinical development for the treatment of inflammatory and autoimmune conditions [16, 37]. VX-765 has been shown to block the release of IL- $1 \beta$ induced by ICE/caspase- 1 activation by proinflammatory stimuli in organotypic hippocampal slices [9, 38]; moreover, VX-765 reduced acute seizures in kainate-treated rats with a concomitant $50 \%$ decrease in hippocampal levels of IL-1 $\beta$ [9]. VX-765 was also able to block generalization of seizures during rapid electrical kindling development in rats, and this effect was associated with prevention of after discharge-induced IL-1 $\beta$ expression in forebrain astrocytes [12]. The anticonvulsant effects of this class of drugs (pralnacasan, VX765) are specifically mediated by ICE/caspase- 1 inhibition because these effects were precluded in mice defective for ICE/caspase-1 gene [9]. These findings, together with the evidence that ICE/caspase-1 knock-out mice are intrinsically less susceptible to kainate seizures [9], strongly supports a key role of ICE/caspase-1 activation in the mechanisms underlying seizure occurrence.

The activation of the IL- $1 \beta$ system in neurons and glia during experimental seizures is corroborated by clinical observations showing overexpression of IL-1 $\beta$ and IL1R1 and induction of ICE/caspase-1 in surgically resected epileptic tissue from individuals with drugresistant seizures [10, 18, 21, 22]. Notably, the expression of IL-1 $\beta$ measured in human epileptogenic tissue positively correlates with the frequency of seizures in the same patients before surgery, highlighting a possible link between the brain level of this cytokine and seizure recurrence [21].
A mechanistic link between IL-1 $\beta$ and N-Methyl-Daspartate (NMDA) receptors has been recently demonstrated to underlie the pro-convulsant action of this cytokine [11]. This mechanism consists of the IL-1R1dependent activation of neuronal sphingomyelinase and Src kinases, resulting in phosphorylation of the NR2B subunit of the NMDA receptors [11, 39] and enhanced NMDA-mediated neuronal $\mathrm{Ca}^{2+}$ influx [39]. Pharmacological interference with this mechanism in vivo prevents the pro-convulsant activity of IL-1 $\beta$ [11]. NR2B-expressing NMDA receptors are considered the main targets of glutamate released by activated astrocytes, leading to neuronal induction of slow inward currents. These slow inward currents have a role in neuronal synchronization and can trigger action potentials in neurons; these currents are increased in models of seizures and their pharmacological inhibition significantly attenuates ictal events [40, 41]; therefore, the currents may represent the crucial molecular event by which IL-1 $\beta$ worsens seizures. IL- $1 \beta$ also inhibits the astrocytic reuptake of glutamate [42] and may increase glutamate release from glia via tumor necrosis factor- $\alpha$ production [43], thus resulting in elevated extracellular glutamate levels that promote hyperexcitability. The inhibition of IL$1 \beta$ production by VX-765 would prevent the increased neuronal excitability mediated by the previously described events, thus reducing epileptic activity. Notably, an antiinflammatory steroid drug, such as dexamethasone [33], which is used for medical treatment of pharmacoresistant seizures ("for details see review by Vezzani et al. [44]") was also effective in this model for partly reducing epileptic activity. The effect of dexamethasone was transient lapsing after $4 \mathrm{~h}$ of treatment. This relatively short-lasting effect as compared to longer biological activity [45] and terminal half-life [46] reported in rats might be due to species differences in dexamethasone pharmacokinetics [46]. Besides its established anti-inflammatory properties, dexamethasone anticonvulsant effect may be mediated by its ability to reverse the increased serum corticosterone concentrations, which are elicited by elevated IL- $1 \beta$ brain levels via activation of the hypothalamic-pituitary adrenal axis (HPA) axis [47, 48]. Thus, chronic high levels of glucorticoids can produce proinflammatory effects in the brain [49] and increase neuronal vulnerability to injury [50, 51]. This mechanism, although still speculative, may also play a role in the anticonvulsant activity of VX-765.

Given the unmet needs in treatment-resistant epilepsy, and the potential role of ICE/IL- $1 \beta$ in seizures, the results from the previous and current pre-clinical studies support testing the hypothesis that inhibition of ICE/ caspase-1 may be useful to treat intractable epilepsy in humans. In a phase 2 clinical study of psoriasis, VX-765 was safe and well tolerated [52-54]. A phase 2 clinical trial is currently underway to assess whether VX-765 can be administered safely and reduces seizures in patients 
with treatment-resistant partial epilepsy when given for a 6-week duration [55]. Pending the results of this initial epilepsy study, it will be important to further understand the safety and efficacy of longer duration treatment with VX-765. Chronic administration is likely to be required, but the potential effects of long-term inhibition of ICE/ caspase-1 are unknown.

In summary, the powerful anticonvulsant effect of VX765 on acute seizures and in chronic epileptic mice not responsive to some conventional AEDs may open new perspectives for a clinical use of selective ICE/caspase-1 inhibitors for the treatment of seizures in pharmacoresistant epileptic disorders. Moreover, because these acute and chronic models of seizures are sensitive to anti-inflammatory drugs, including antagonists of tolllike receptor 4 [25], they may be useful to develop pharmacological attempts to block brain inflammation for attaining seizure control.

Acknowledgments: This study was supported by EPICURE (LSH-CT-2006-037315) (A.V.) and Fondazione Monzino (A. V.). Mattia Maroso received a fellowship from NeuroGlia (EUFP7-project 202167). The authors are grateful to Vertex Pharmaceuticals Inc. for supplying VX-765 and to Irina Kadiyala (Vertex Pharmaceuticals Inc.) for her support with the drug formulation. Dr. C. I. Wright is employed at Vertex Pharmaceuticals Inc. We also thank Dr. F. Noé and Dr. M. de Curtis for their valuable contribution in EEG tracing analysis. Full conflict of interest disclosure is available in the electronic supplementary material for this article.

\section{References}

1. Vezzani A, Balosso S, Ravizza T. The role of cytokines in the pathophysiology of epilepsy. Brain Behav Immun 2008;22:797-803.

2. Ravizza T, Balosso S, Aronica E, Vezzani A. Brain Inflammation and epilepsy. In: Rho JM, Sankar R, Strafstrom CE, eds. Epilepsy: mechanisms, models, and translational perpsectives. Boca Raton, FL: CRC Press; 2010:45-59.

3. Minami M, Kuraishi Y, Satoh M. Effects of kainic acid on messenger RNA levels of IL-1 beta, IL-6, TNF alpha and LIF in the rat brain. Biochem Biophys Res Commun 1991;176:593-598.

4. Eriksson C, Van Dam AM, Lucassen PJ, Bol JG, Winblad B, Schultzberg M. Immunohistochemical localization of interleukin1beta, interleukin-1 receptor antagonist and interleukin-1beta converting enzyme/caspase-1 in the rat brain after peripheral administration of kainic acid. Neuroscience 1999;93:915-930.

5. Vezzani A, Conti M, De Luigi A, et al. Interleukin-1beta immunoreactivity and microglia are enhanced in the rat hippocampus by focal kainate application: functional evidence for enhancement of electrographic seizures. J Neurosci 1999;19:5054-5065.

6. De Simoni MG, Perego C, Ravizza $T$, et al. Inflammatory cytokines and related genes are induced in the rat hippocampus by limbic status epilepticus. Eur J Neurosci 2000;12:2623-2633.

7. Dubé C, Vezzani A, Behrens M, Bartfai T, Baram TZ. Interleukin1beta contributes to the generation of experimental febrile seizures. Ann Neurol 2005;57:152-155.

8. Heida JG, Moshe SL, Pittman QJ. The role of interleukin-1beta in febrile seizures. Brain Dev 2009;31:388-393.

9. Ravizza T, Lucas SM, Balosso S, et al. Inactivation of caspase-1 in rodent brain: a novel anticonvulsive strategy. Epilepsia 2006;47:1160-1168.
10. Ravizza T, Gagliardi B, Noé F, Boer K, Aronica E, Vezzani A. Innate and adaptive immunity during epileptogenesis and spontaneous seizures: evidence from experimental models and human temporal lobe epilepsy. Neurobiol Dis 2008;29:142-160.

11. Balosso S, Maroso M, Sanchez-Alavez M, et al. A novel nontranscriptional pathway mediates the proconvulsive effects of interleukin-1beta. Brain 2008;131:3256-3265.

12. Ravizza T, Noé F, Zardoni D, Vaghi V, Sifringer M, Vezzani A. Interleukin converting enzyme inhibition impairs kindling epileptogenesis in rats by blocking astrocytic IL-1beta production. Neurobiol Dis 2008;31:327-333.

13. Vezzani A, Moneta D, Conti M, et al. Powerful anticonvulsant action of IL-1 receptor antagonist on intracerebral injection and astrocytic overexpression in mice. Proc Natl Acad Sci U S A 2000;97:11534-11539.

14. Vezzani A, Moneta D, Richichi C, et al. Functional role of inflammatory cytokines and antiinflammatory molecules in seizures and epileptogenesis. Epilepsia 2002;43(suppl 5):30-35.

15. Marchi N, Fan Q, Ghosh C, et al. Antagonism of peripheral inflammation reduces the severity of status epilepticus. Neurobiol Dis 2009;33:171-181.

16. Randle JC, Harding MW, Ku G, Schonharting M, Kurrle R. ICE/ Caspase-1 inhibitors as novel anti-inflammatory drugs. Expert Opin Investig Drugs 2001;10:1207-1209.

17. Fantuzzi G, Dinarello CA. Interleukin-18 and interleukin-1 beta: two cytokine substrates for ICE (caspase-1). J Clin Immunol 1999;19:1-11,

18. Henshall DC, Clark RS, Adelson PD, Chen M, Watkins SC, Simon RP. Alterations in bcl-2 and caspase gene family protein expression in human temporal lobe epilepsy. Neurology 2000;55:250-257.

19. Sheng JG, Boop FA, Mrak RE, Griffin WS. Increased neuronal beta-amyloid precursor protein expression in human temporal lobe epilepsy: association with interleukin-1 alpha immunoreactivity. J Neurochem 1994;63:1872-1879.

20. Crespel A, Coubes P, Rousset MC, et al. Inflammatory reactions in human medial temporal lobe epilepsy with hippocampal sclerosis. Brain Res 2002;952:159-169.

21. Ravizza T, Boer K, Redeker S, et al. The IL-1beta system in epilepsy-associated malformations of cortical development. Neurobiol Dis 2006;24:128-143.

22. Boer K, Jansen F, Nellist M, et al. Inflammatory processes in cortical tubers and subependymal giant cell tumors of tuberous sclerosis complex. Epilepsy Res 2008;78:7-21.

23. Bouilleret V, Ridoux V, Depaulis A, Marescaux C, Nehlig A, Le Gal La Salle G. Recurrent seizures and hippocampal sclerosis following intrahippocampal kainate injection in adult mice: electroencephalography, histopathology and synaptic reorganization similar to mesial temporal lobe epilepsy. Neuroscience 1999;89:717-729.

24. Riban V, Bouilleret V, Pham-Le BT, Fritschy JM, Marescaux C, Depaulis A. Evolution of hippocampal epileptic activity during the development of hippocampal sclerosis in a mouse model of temporal lobe epilepsy. Neuroscience 2002;112:101-111.

25. Maroso M, Balosso S, Ravizza T, et al. Toll-like receptor 4 and high-mobility group box-1 are involved in ictogenesis and can be targeted to reduce seizures. Nat Med 2010;16:413-419.

26. Balosso S, Ravizza T, Perego C, et al. Tumor necrosis factor-alpha inhibits seizures in mice via p75 receptors. Ann Neurol 2005;57:804-812.

27. Antonucci F, Di Garbo A, Novelli E, et al. Botulinum neurotoxin $\mathrm{E}$ (BoNT/E) reduces CA1 neuron loss and granule cell dispersion, with no effects on chronic seizures, in a mouse model of temporal lobe epilepsy. Exp Neurol 2008;210:388-401.

28. Kralic JE, Ledergerber DA, Fritschy JM. Disruption of the neurogenic potential of the dentate gyrus in a mouse model of temporal lobe epilepsy with focal seizures. Eur J Neurosci 2005;22:1916-1927.

29. Suzuki F, Heinrich C, Boehrer A, et al. Glutamate receptor antagonists and benzodiazepine inhibit the progression of granule cell dispersion in a mouse model of mesial temporal lobe epilepsy. Epilepsia 2005;46:193-202.

30. Paxinos KB. The mouse brain in stereotaxic coordinates. San Diego: Academic Press, 1997.

31. Costantin L, Bozzi Y, Richichi C, et al. Antiepileptic effects of botulinum neurotoxin E. J Neurosci 2005;25:1943-1951. 
32. Ji-qun C, Ishihara K, Nagayama T, Serikawa T, Sasa M. Longlasting antiepileptic effects of levetiracetam against epileptic seizures in the spontaneously epileptic rat (SER): differentiation of levetiracetam from conventional antiepileptic drugs. Epilepsia 2005;46:1362-1370

33. Zuckerman SH, Bendele AM. Regulation of serum tumor necrosis factor in glucocorticoid-sensitive and -resistant rodent endotoxin shock models. Infect Immun 1989;57:3009-3013.

34. Ravizza T, Vezzani A. Status epilepticus induces time-dependent neuronal and astrocytic expression of interleukin-1 receptor type I in the rat limbic system. Neuroscience 2006;137:301-308.

35. Zangaladze A, Nei M, Liporace JD, Sperling MR. Characteristics and clinical significance of subclinical seizures. Epilepsia 2008;49:2016-2021.

36. Sperling MR, O'Connor MJ. Auras and subclinical seizures: characteristics and prognostic significance. Ann Neurol 1990;28:320-328.

37. Stack JH, Beaumont K, Larsen PD, et al. IL-converting enzyme/ caspase-1 inhibitor VX-765 blocks the hypersensitive response to an inflammatory stimulus in monocytes from familial cold autoinflammatory syndrome patients. J Immunol 2005;175:2630-2634.

38. Bernardino L, Balosso S, Ravizza T, et al. Inflammatory events in hippocampal slice cultures prime neuronal susceptibility to excitotoxic injury: a crucial role of $\mathrm{P} 2 \mathrm{X} 7$ receptor-mediated IL-1beta release. J Neurochem 2008;106:271-280.

39. Viviani B, Bartesaghi S, Gardoni F, et al. Interleukin-1beta enhances NMDA receptor-mediated intracellular calcium increase through activation of the Src family of kinases. J Neurosci 2003;23:8692-8700

40. Fellin T. Communication between neurons and astrocytes: relevance to the modulation of synaptic and network activity. J Neurochem 2009;108:533-544.

41. Fellin T, Gomez-Gonzalo M, Gobbo S, Carmignoto G, Haydon PG. Astrocytic glutamate is not necessary for the generation of epileptiform neuronal activity in hippocampal slices. J Neurosci 2006;26:9312-9322.

42. Hu S, Sheng WS, Ehrlich LC, Peterson PK, Chao CC. Cytokine effects on glutamate uptake by human astrocytes. Neuroimmunomodulation 2000;7:153-159.
43. Bezzi P, Domercq M, Brambilla L, et al. CXCR4-activated astrocyte glutamate release via TNFalpha: amplification by microglia triggers neurotoxicity. Nat Neurosci 2001;4:702-710.

44. Vezzani A, French J, Bartfai T, Baram TZ. The role of inflammation in epilepsy. Nat Rev Neurol 2011;7:31-40.

45. Steimer T, Python A, Schulz PE, Aubry JM. Plasma corticosterone, dexamethasone (DEX) suppression and DEX/CRH tests in a rat model of genetic vulnerability to depression. Psychoneuroendocrinology 2007;32:575-579.

46. Hansen DK, LaBorde JB, Wall KS, Holson RR, Young JF. Pharmacokinetic considerations of dexamethasone-induced developmental toxicity in rats. Toxicol Sci 1999;48:230-239.

47. Buckingham JC, Loxley HD, Taylor AD, Flower RJ. Cytokines, glucocorticoids and neuroendocrine function. Pharmacol Res 1994:30:35-42.

48. Goshen I, Yirmiya R. Interleukin-1 (IL-1): a central regulator of stress responses. Front Neuroendocrinol 2009;30:30-45.

49. Dinkel K, MacPherson A, Sapolsky RM. Novel glucocorticoid effects on acute inflammation in the CNS. J Neurochem 2003;84:705-716.

50. Sapolsky RM. A mechanism for glucocorticoid toxicity in the hippocampus: increased neuronal vulnerability to metabolic insults. J Neurosci 1985;5:1228-1232.

51. Stein-Behrens BA, Elliott EM, Miller CA, Schilling JW, Newcombe R, Sapolsky RM. Glucocorticoids exacerbate kainic acid-induced extracellular accumulation of excitatory amino acids in the rat hippocampus. J Neurochem 1992;58:1730-1735.

52. Imperato AK, Bingham $\mathrm{CO} 3 \mathrm{rd}$, Abramson SB. Overview of benefit/risk of biological agents. Clin Exp Rheumatol 2004;22: S108-S114

53. Cornelis S, Kersse K, Festjens N, Lamkanfi M, Vandenabeele P. Inflammatory caspases: targets for novel therapies. Curr Pharm Des 2007; 13:367-385

54. Vezzani A, Balosso S, Maroso M, Zardoni D, Noé F, Ravizza T. ICE/ caspase 1 inhibitors and IL-1beta receptor antagonists as potential therapeutics in epilepsy. Curr Opin Investig Drugs 2010;11:43-50.

55. ClinicalTrials.gov. Study of VX-765 in subjects with treatmentresistant partial epilepsy [online], 2010. Available at: http:/ clinicaltrials.gov/ct2/show/NCT01048255. 